\section{Heart age woes: unnecessarily testing}

On receiving a link in my local authority's e-newsletter, I entered my details in Public Health England's 'One You' online heart age checker., ${ }^{1,2}$ I am a 34 year-old, male, non-smoker, (BMI) 21.5, normal systolic blood pressure $(113 \mathrm{mmHg})$, cholesterol unknown, with no family history or other risk factors for heart disease. I was told my heart age is 34 and given lifestyle advice.

However, I was then told my cholesterol 'Is not known - GET TESTED' in large red letters, and that, although I wouldn't be automatically invited by my GP to have my cholesterol checked, I should get into the habit of 'knowing my numbers'.

Using the information I provided (without cholesterol), my QRisk2 score could easily be calculated at $0.6 \%{ }^{3}$ Even if my cholesterol was raised, statin medication would not be indicated according to current guidelines, but rather lifestyle advice, ${ }^{4}$ which was recommended anyway.

Despite large meta-analyses, there is no evidence that cardiovascular screening of asymptomatic subjects reduces mortality or morbidity, with little attention paid to the harms of screening in studies to date. ${ }^{5}$ There remain significant concerns about the clinical and cost-effectiveness of the politically driven NHS Health Check Programme for 40-74-year-olds. ${ }^{6}$ The likelihood of benefit of cholesterol screening in younger groups under 40 years seems even more unlikely.

All this when the NHS and primary care are under huge strain trying to provide evidence-based care that is actually needed. Why is this irresponsible advice being given and when will it be changed?

Alexander Gilkes,

GP Research Fellow, School of Population Health Sciences, Faculty of Life Sciences and Medicine, King's College London,

London.

Email: alexander.gilkeslakcl.ac.uk

\section{REFERENCES}

1. Jones R. Hard data. Br J Gen Pract 2018; DOI: https://doi.org/10.3399/bjgp18X694865.

2. Public Health England. One you: check your heart age. 2018. https://mww.nhs.uk/oneyou/ hat\#rUi4wf1 mmpUVEuGb.97 laccessed 9 Apr 2018).

3. ClinRisk Ltd. Qrisk2-2017 risk calculator. 2017. https://qrisk.org/2017/index.php laccessed 9 Apr 2018).
4. National Institute for Health and Care Excellence. Cardiovascular disease: risk assessment and reduction, including lipid modification. CG181. London: NICE, 2014. https://www.nice.org.uk/ guidance/cg181 laccessed 9 Apr 2018).

5. Krogsbøll LT, Jørgensen KJ, Grønhøj Larsen C, Gøtzsche PC. General health checks in adults for reducing morbidity and mortality from disease: Cochrane systematic review and meta-analysis. BMJ 2012; 345: e7191.

6. Capewell S, McCartney M, Holland W. Invited debate: NHS Health Checks - a naked emperor? J Public Health (Oxf) 2015; 37(2): 187-192.

DOI: https://doi.org/10.3399/bjgp18X695921

\section{Screening for thyroid dysfunction in patients with diabetes}

This was an interesting article; however, its usefulness was limited because of the lack of clarity about what makes for effective screening.

Any screening proposals should be subject to the Wilson/Jungner criteria for an effective screening programme. This is presumably what the US Taskforce and UK National Screening Committee have done, concluding that there is insufficient evidence of benefit. As screening always has the potential for harms as well as benefits, the criteria for effective screening programmes must always be to the forefront of any discussion. It was disappointing that this was not done in this article.

Specialist interest groups often seem to be more enthusiastic about screening than the evidence supports, hence the objective approach of the National Screening Committee is necessary and should be respected.

Avril Danczak,

GP Primary Care Medical Educator, Health Education England North West.

Email: avril.danczaklabtinternet.com

\section{REFERENCE}

1. Ward RJ, Heald AH, Ogunmekan S, et al. Should we be screening for thyroid dysfunction in patients with type 2 diabetes mellitus? Br J Gen Pract 2018; DOI: https://doi.org/10.3399/bjgp18X694793.

DOI: https://doi.org/10.3399/bjgp18X695933

\section{Dare to think rare: diagnostic delay and rare diseases}

I welcome the Debate and Analysis piece 'Preventing gatekeeping delays in the diagnosis of rare disease' by Esther de Vries and colleagues.' Discussion about how we can improve the diagnostic delay for patients with rare diseases, on average 4.8 years, ${ }^{2}$ is much needed.

The use of the term 'Gatekeeper' is often associated with negative connotations, simply preventing the patients accessing the health care they need. I see the 'gatekeeper' role as more collaborative, navigating the patient through a complicated healthcare field.

For many patients with rare diseases, their 'diagnostic odyssey' has little to do with delayed referral from primary care; rather, the diagnostic delay is despite referral and involvement of multiple clinical centres, specialties, and investigations. Indeed, it is this complicated and sometimes fragmented care, poor communication, and lack of a whole patient view, highlighted in this article, that can be the principal barrier to diagnosis. The information to make a diagnosis is available but not joined up.

It is in this capacity that we as primary care physicians, perhaps the last true generalists with a whole-person approach, can see through this fragmented noise and join the dots. De Vries et al discuss the use of 'gut feeling' identifying divergent patterns as the prompt for further enquiry. ${ }^{1}$ I strongly endorse this approach. Knowledge of all 6000-8000 rare diseases, ${ }^{3}$ increasing each week, is impossible for any one individual. The response 'How can we know about all rare disease?' is not only true but also feeds into the cognitive barrier that prevents clinicians contemplating a rare disease at all.

Simply following one's 'gut feeling', asking is there a more plausible explanation that may include a rare disease, is the first step. Help with where to go next is normally readily available from local clinical genetic departments or, if appropriate, metabolic centres; there are also useful web-based rare disease search engines such as omim.org and findzebra.com, into which simply typing clinical features gives a list of differential diagnoses. ${ }^{4}$

But the first step is to remember: 'Dare to think rare.

William RH Evans, 